$10-2019$

\title{
Beliefs and Use of Intrauterine Devices (IUDs) Among Women's Health Care Providers
}

\author{
Christa Esposito \\ Fairfield University, christa.esposito@fairfield.edu \\ Jenna A. LoGiudice \\ Fairfield University, jlogiudice@fairfield.edu
}

Follow this and additional works at: https://digitalcommons.fairfield.edu/nursing-facultypubs

(c) 2019 Elsevier Inc. All rights reserved.

A post-print has been archived here for authorized subscribers.

\section{Peer Reviewed}

\section{Repository Citation}

Esposito, Christa and LoGiudice, Jenna A., "Beliefs and Use of Intrauterine Devices (IUDs) Among Women's Health Care Providers" (2019). Nursing and Health Studies Faculty Publications. 208.

https://digitalcommons.fairfield.edu/nursing-facultypubs/208

\section{Published Citation}

Esposito, C. P., \& LoGiudice, J. (Oct 2019). Beliefs and Use of Intrauterine Devices (IUDs) Among Women's Health Care Providers. The Journal for Nurse Practitioners 15 (9) pp.682-687. 10.1016/j.nurpra.2019.05.005

This item has been accepted for inclusion in DigitalCommons@Fairfield by an authorized administrator of DigitalCommons@Fairfield. It is brought to you by DigitalCommons@Fairfield with permission from the rightsholder(s) and is protected by copyright and/or related rights. You are free to use this item in any way that is permitted by the copyright and related rights legislation that applies to your use. For other uses, you need to obtain permission from the rights-holder(s) directly, unless additional rights are indicated by a Creative Commons license in the record and/or on the work itself. For more information, please contact digitalcommons@fairfield.edu. 


\section{Beliefs and Use of Intrauterine Devices (IUDs) Among Women's Health Care Providers}

\section{Christa Palancia Esposito, DNP, CNM}

\section{Jenna LoGiudice, PhD, CNM}

In compliance with national ethical guidelines, the authors report no relationships with business or industry that would pose a conflict of interest.

\section{Abstract}

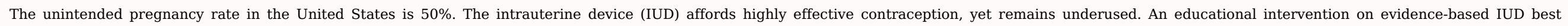

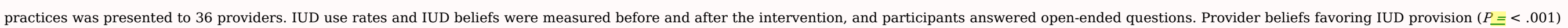

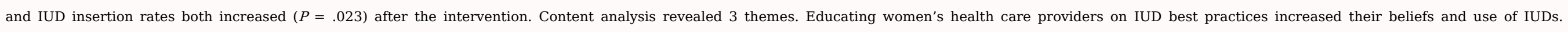
Continuing education enhances provision of the IUD, thereby reducing unintended pregnancies.

Keywords: intrauterine device; IUD; long-acting reversible contraception; unintended pregnancy; women's health care provider beliefs

\section{Introduction}

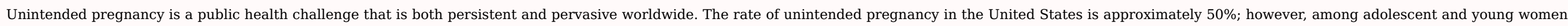
this number is much higher at $82 \% .{ }^{1}$ Moreover, women younger than 25 years have higher rates of contraception failure and pregnancy-related morbidity compared with women older than 25 years. ${ }^{2}$

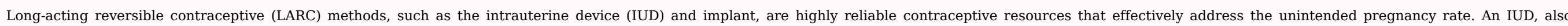

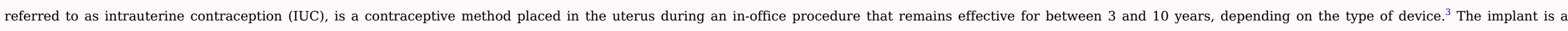

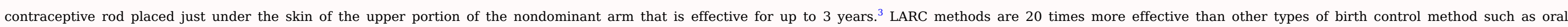
contraceptives. ${ }^{3}$

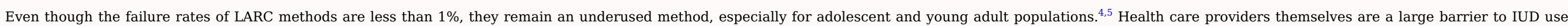
given that not all providers adhere to current IUD best practices. ${ }^{6}$

\section{Background and Significance}

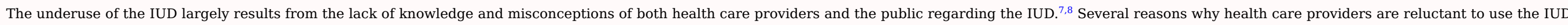

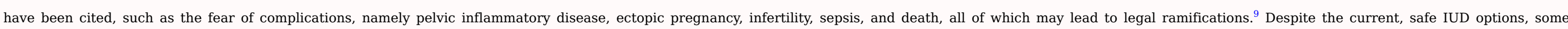
providers recall past issues from nearly 50 years ago when IUDs, like the Dalkon Shield in the 1970s, were linked to these complications. ${ }^{10}$

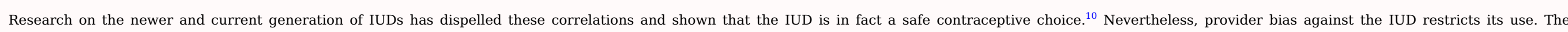

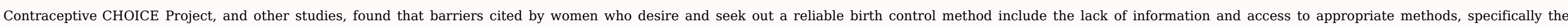
IUD. ${ }^{8,11,12}$ In the US, only $11.8 \%$ of women currently use an IUD. ${ }^{13}$

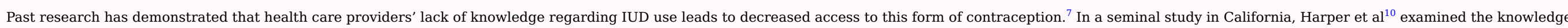

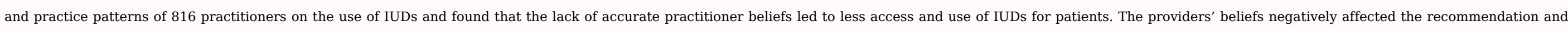

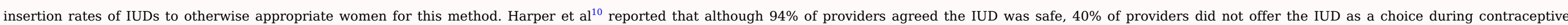




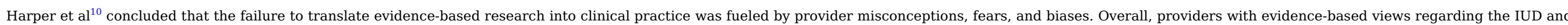

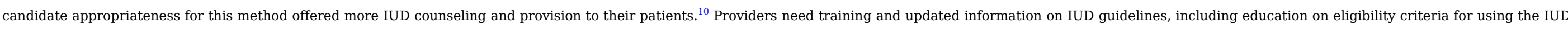

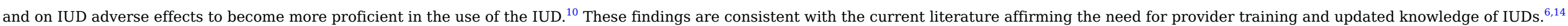

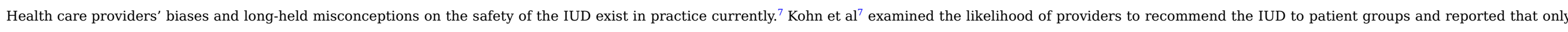

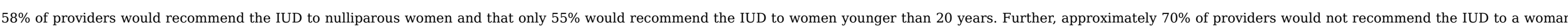

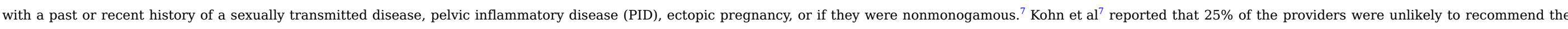
IUD to nulliparous women even though $86 \%$ knew that the IUD was safe as a contraceptive option for this population

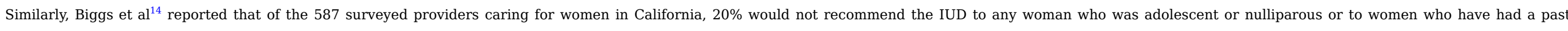

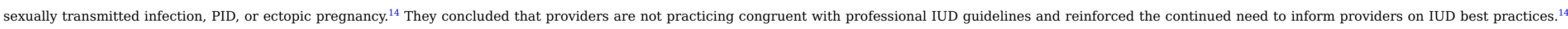

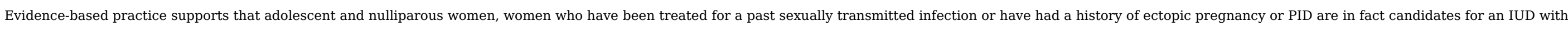
the appropriate screening and counseling. ${ }^{14}$ Ongoing provider training has been found to increase IUD best practices and use. ${ }^{15}$

\section{Purpose}

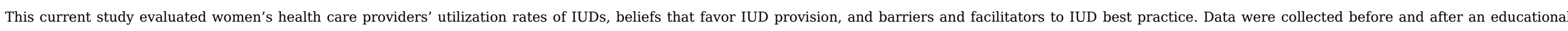
intervention and IUD policy presentation.

\section{Methods}

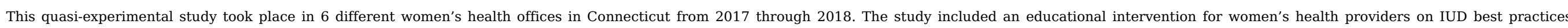
delivered by the first author. The intervention incorporated the presentation of an IUD policy, adapted from the publicly available Reproductive Health Access Project. ${ }^{16}$

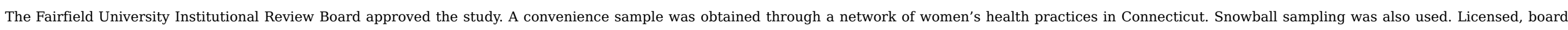

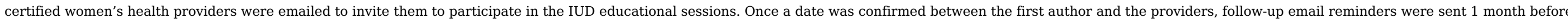

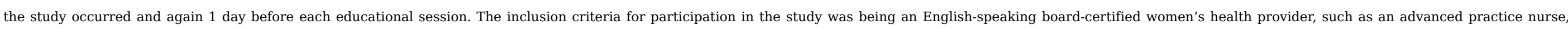
certified nurse midwife, physician assistant, or physician, with at least 1 year of practice experience. The study excluded office staff and medical assistants.

\section{Intervention}

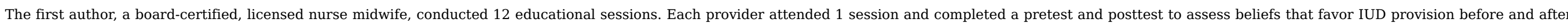

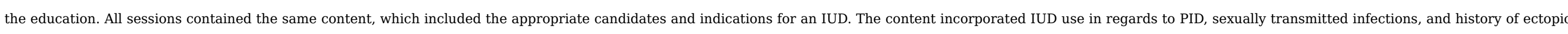

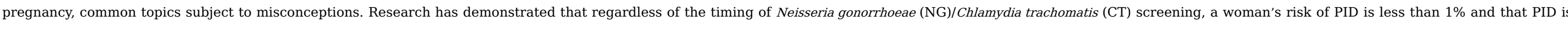

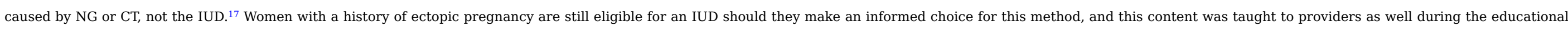
sessions.

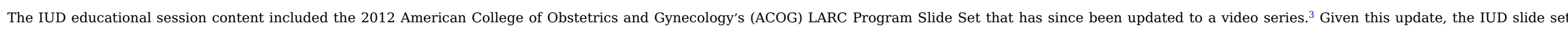

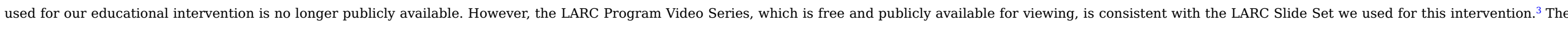

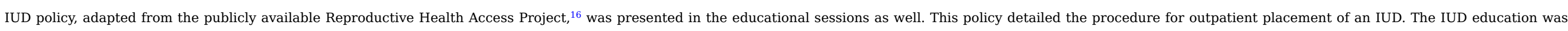
offered in an objective, noncoercive manner presenting factual IUD best practices.

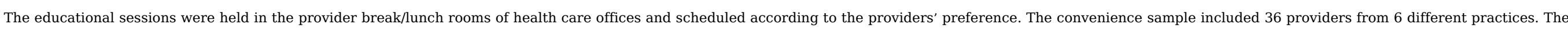

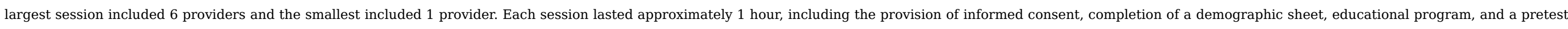




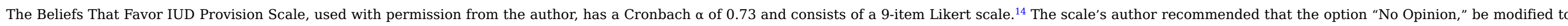

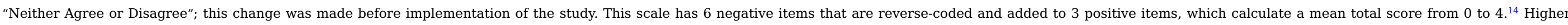

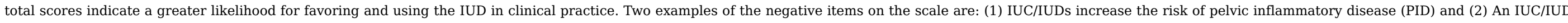

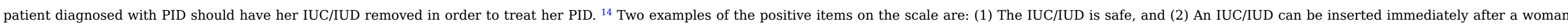
has an abortion.

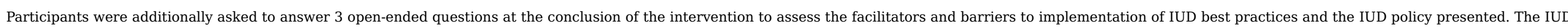
utilization rates of each provider were collected using a medical record review in which billing codes for IUD insertions 2 months before and 2 months after the education intervention were analyzed.

\section{Quantitative Data Analysis}

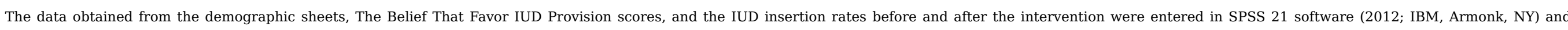
reviewed for accuracy. Statistical analysis included matched paired $t$ tests on each participant for their beliefs that favor IUD provision scores and their IUD insertion rates before and after the intervention

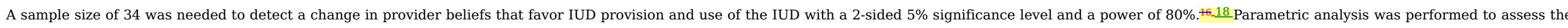

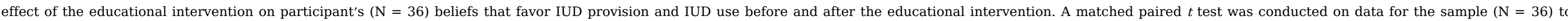

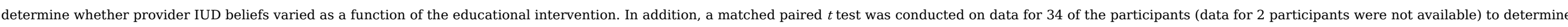
whether provider IUD use varied as a function of the educational intervention.

\section{Qualitative Data Analysis}

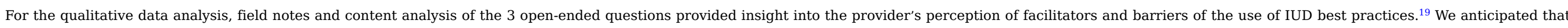

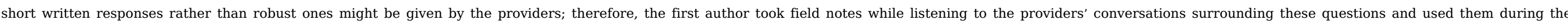
qualitative data analysis.

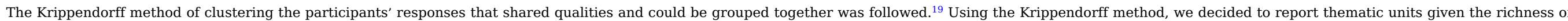

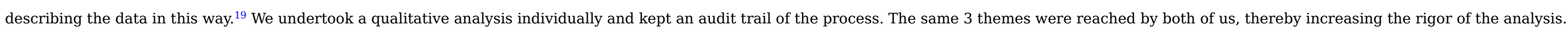

\section{Results}

\section{Quantitative}

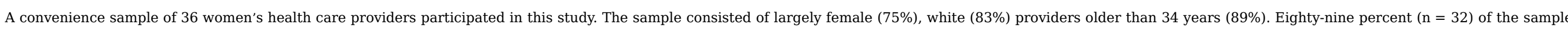

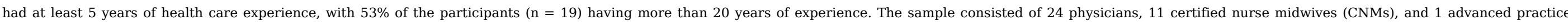

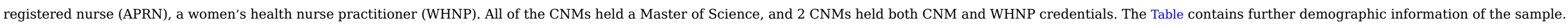

Table Women's Health Provider Characteristics

\begin{tabular}{|c|c|}
\hline \multicolumn{2}{|c|}{ Demographic information } \\
\hline & $(\mathrm{N}=35 \underline{36})$ \\
\hline \multicolumn{2}{|l|}{ Sex } \\
\hline Male & $9(25)$ \\
\hline Female & 27 (75) \\
\hline Age, y & $\underline{\mathrm{n}=35}$ \\
\hline
\end{tabular}




\begin{tabular}{|c|c|}
\hline $25-35$ & $4(11)$ \\
\hline $35-45$ & $8(23)$ \\
\hline $45-55$ & $8(23)$ \\
\hline $55-65$ & $10(29)$ \\
\hline$\geq 65$ & $5(14)$ \\
\hline Race/ethnicity & $\underline{\mathrm{n}=35}$ \\
\hline African American & 0 \\
\hline Asian & $3(1)$ \\
\hline White & $29(83)$ \\
\hline Hispanic & 0 \\
\hline Asian/African American & $1(.03)$ \\
\hline Other & $2(.06)$ \\
\hline \multicolumn{2}{|l|}{ Education } \\
\hline Masters & $10(28)$ \\
\hline Doctorate & $22(61)$ \\
\hline Other & $4(11)$ \\
\hline \multicolumn{2}{|l|}{ Years of experience } \\
\hline $1-5$ & $4(11)$ \\
\hline $5-10$ & $4(11)$ \\
\hline $10-20$ & $9(25)$ \\
\hline$>20$ & $19(53)$ \\
\hline \multicolumn{2}{|l|}{ Degree type (all that apply) } \\
\hline $\mathrm{DO} / \mathrm{MD}$ & $24(67)$ \\
\hline $\mathrm{CNM}$ & $9(25)$ \\
\hline APRN & $3(1)$ \\
\hline DNP & 0 \\
\hline $\mathrm{PhD}$ & 0 \\
\hline PA & 0 \\
\hline
\end{tabular}

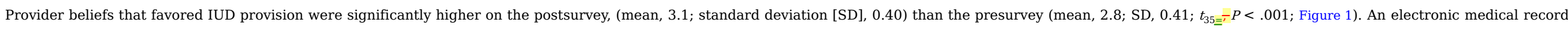

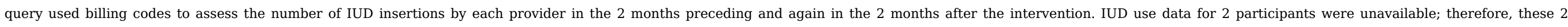

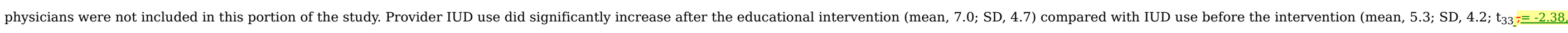
$P=.023$; Figures 2 and 3 ). 


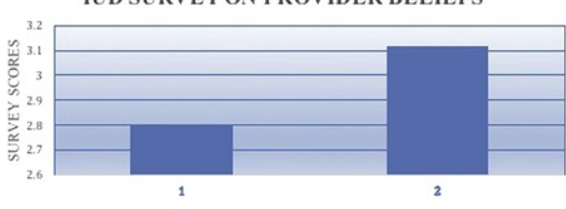

Pre survey

Post survey

Figure 1 Presurvey and postsurvey scores. $P<.001$

Individual Provider IUD Insertion Rates

Before IUD Rate $\quad$ After IUD Rate

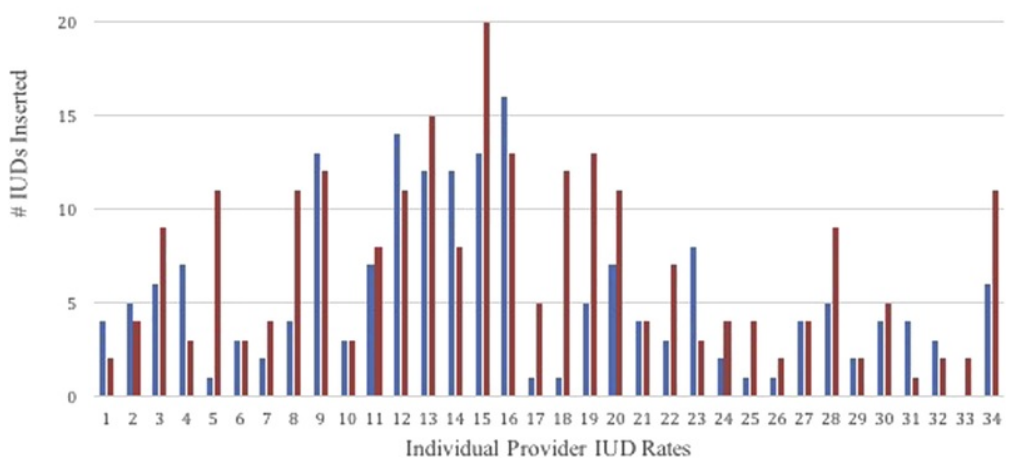

Figure 2 Individual provider intrauterine device (IUD) insertion rates before and after the intervention.

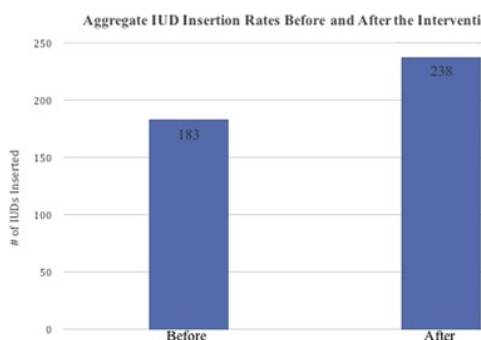

Figure 3 Aggregate intrauterine device $(I U D)$ insertion rates before and after the intervention. $P=.023$.

\section{Qualitative}

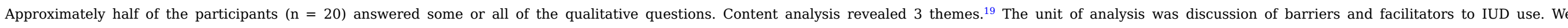
independently clustered the data, forming 3 themes each, and had consensus on the themes.

Theme 1 "Already doing it." Providers felt that they were, "already doing it" and would keep using the IUD, and this theme represents a facilitator to IUD use.

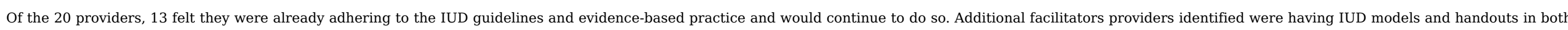

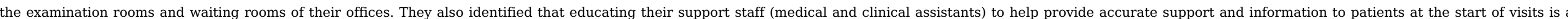
facilitator to IUD use. 


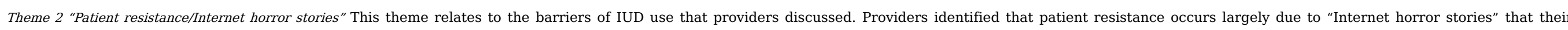
patient has read online.

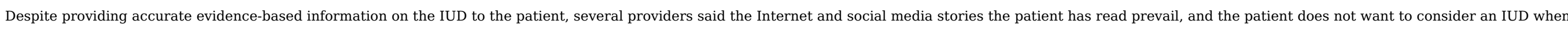

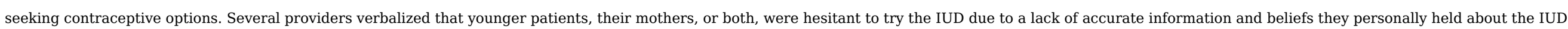

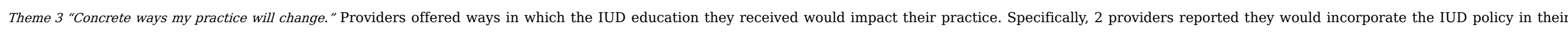

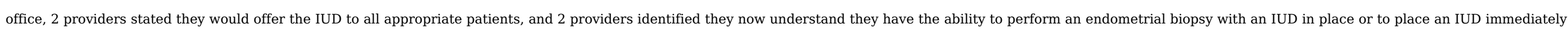
after delivery or after termination of pregnancy. They had learned of new categories of women who are eligible for this contraceptive method from the education intervention.

\section{Discussion}

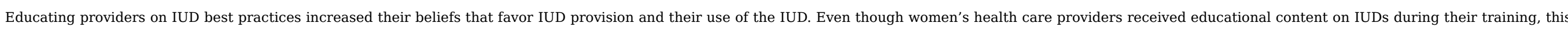
study highlights the importance of continuing education on IUD best practices as a means to increase women's access to this contraceptive method.

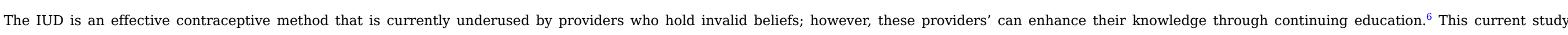

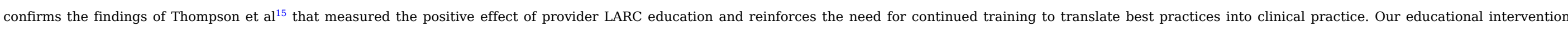

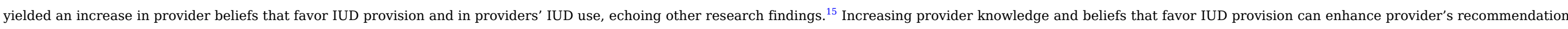
and use of the IUD, thereby decreasing the number of unintended pregnancies.

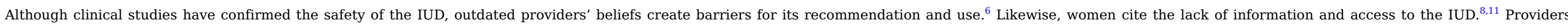

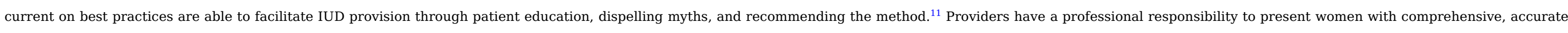
information from which women can make an informed decision regarding their contraception.

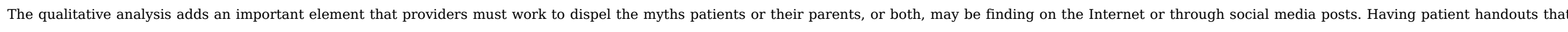

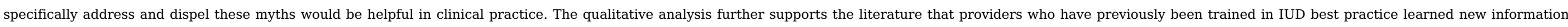
from this current study's intervention about the eligibility of women for the IUD. These providers clearly stated that they would put this new information into their own clinical practice.

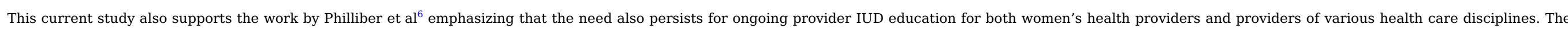

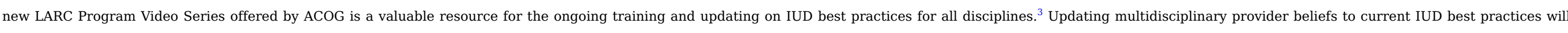
afford all populations of women access to appropriate contraception and decrease the rate of unintended pregnancy.

\section{Limitations}

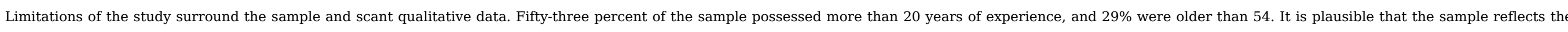

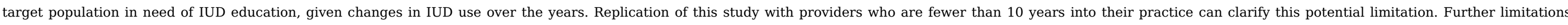
include a fairly homogenous sample of women's health care providers practicing in 1 New England state. Most the sample was white and female.

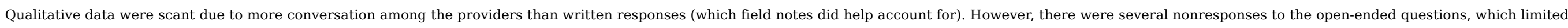
the depth of this portion of this study.

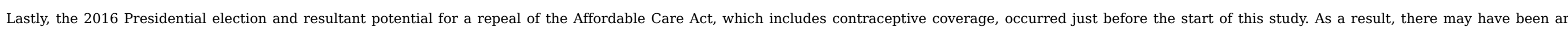

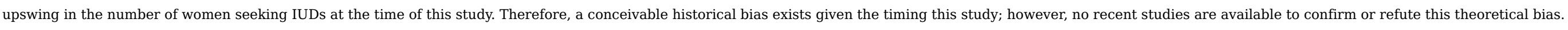

\section{Implications for Clinical Practice}

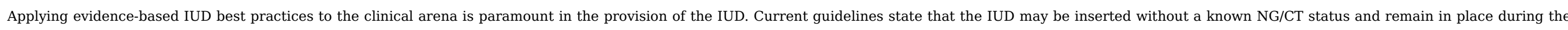




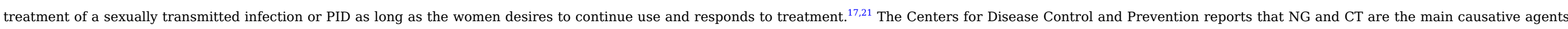
for PID; it $\underline{\mathrm{CT}}$ is considered cured 1 week after treatment with a 1-time 1-g dose of azithromycin. Screening for NG/CT may be done at the same time as the insertion for high-risk patients. ${ }^{17,21}$

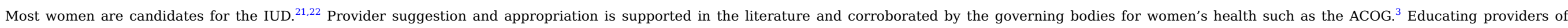

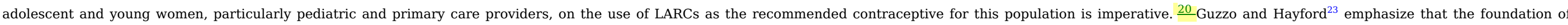

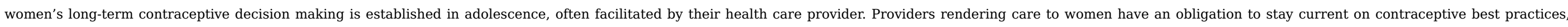
particularly LARC, and educate and offer women an appropriate method through shared decision making.

\section{Implications for Future Research}

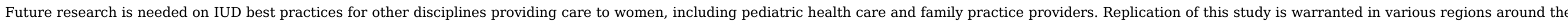

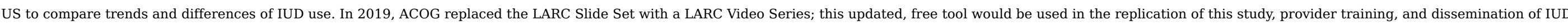
best practices.

\section{Conclusion}

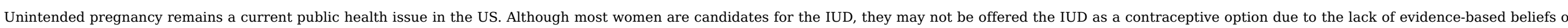

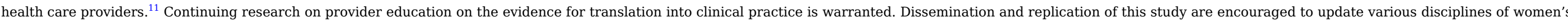

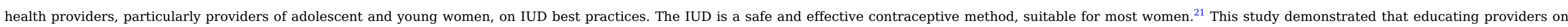
IUD best practices enhanced the provision of the IUD, thereby decreasing women's unintended pregnancy rate.

\section{Uncited References}

18,20

\section{References}

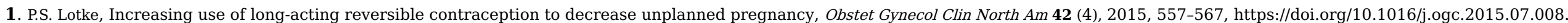

2. J. Krashin, J.H. Tang, S. Mody and L.M. Lopez, Hormonal and intrauterine methods for contraception for women aged 25 years and younger, Cochrane Database Syst Rev 2015 (1), $2015,1-41$ https://doi:10.1002/14651858.CD009805.pub3.

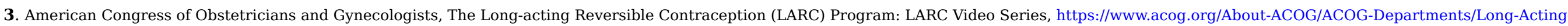
Reversible-Contraception/LARC-Video-Series, Accessed 18 March 2019.

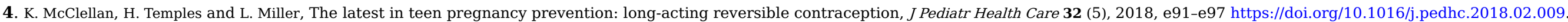

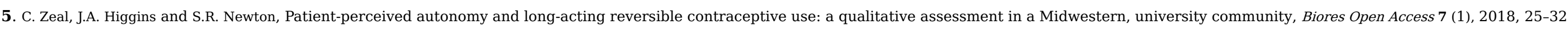
https://doi.org/10.1089/biores.2017.0037.

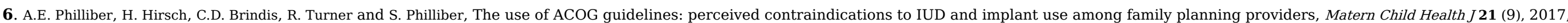
1706-1712 https://doi.org/10.1007/s10995-017-2320-1.

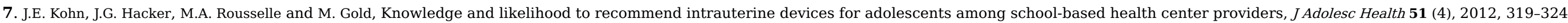
https://doi.org/10.1016/j.jadohealth.2011.12.024.

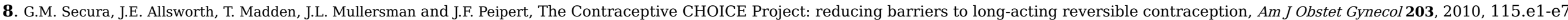
https://doi.org/10.1016/j.ajog.2010.04.017 https://fairfield.primo.exlibrisgroup.com/discovery/fulldisplay?docid=sciversesciencedirect_elsevierS0002-9378(10)00430- 


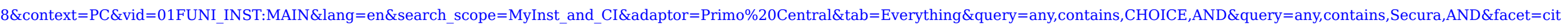
Accessed 2 May 2019.

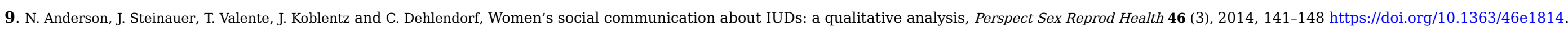

10. C.C. Harper, M. Blum, H. Thiel de Bocanegra, et al., Challenges in translating evidence to practice: the provision of intrauterine contraception, Obstet Gynecol 111 (6), 2008, 1359-1369 https://journals.lww.com/greenjournal/Fulltext/2008/06000/Obstetrician_Gynecologists_and_the_Intrauterine.17.aspx, Accessed 21 March 2019.

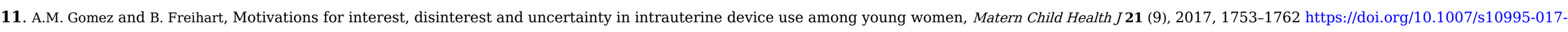
2297-9.

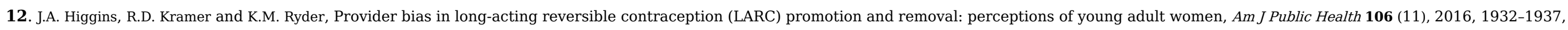
https://doi.org/10.2105/AJPH.2016.303393.

13. M.L. Kavanaugh and J. Jerman, Contraceptive method use in the United States: trends and characteristics between 2008,2012 and 2014 , Contraception 97 (1), 2018, 14-21 https://doi.org/10.1016/j.contraception.2017.10.003.

14. M.A. Biggs, C.C. Harper, J. Malvin and C.D. Brindis, Factors influencing the provision of long-acting reversible contraception in California, Obstet Gynecol 123 (3), 2014, 593-602, https://doi.org/10.1097/AOG.0000000000000137.

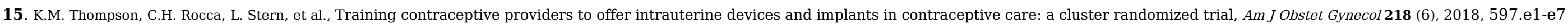
https://doi.org/10.1016/j.ajog.2018.03.016.

16. Reproductive Health Access Project, Policy and procedure for IUDs, http://www.reproductiveaccess.org/resource/iud-policy-procedure. March 21,2015 , Accessed 18 March 2019.

17. Centers for Disease Control and Prevention, 2015 Sexually Transmitted Diseases Treatment Guidelines, https://www.cdc.gov/std/tg2015/default.htm, Accessed 21 March 2019.

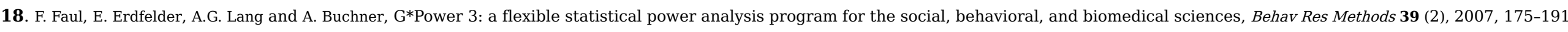
http://www.gpower.hhu.de/en.html, Accessed 12 March 2018.

19. K. Krippendorff, Content Analysis. An Introduction to Its Methodology, 4th ed., 2019, Sage Publications; Thousand Oaks, CA.

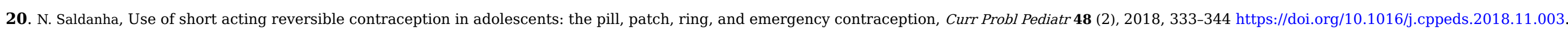

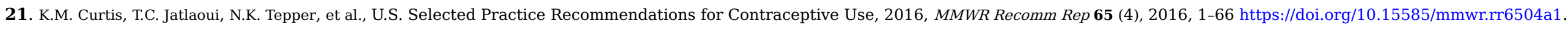

22. K.M. Curtis, N.K. Tepper, T.C. Jatlaoui, et al., Centers for Disease Control and Prevention. U.S. medical eligibility criteria for contraceptive use, 2016 , MMWR Recomm Rep 65 (3), 2016 , 1-104.

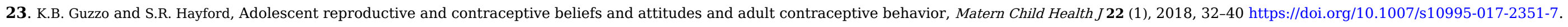
Both authors are at Fairfield University in Fairfield, CT. Christa Palancia Esposito, DNP, CNM, is an Assistant Professor tisiting instructorand can be reached at christa.esposito@fairfield.edu. Jenna LoGiudice, PhD, CNM, is an instructorAssociate Professor and can be reached at jlogiudice@fairfield.edu.

\section{Highlights}

- The intrauterine device (IUD) is a safe and effective contraceptive method, suitable for most women.

- Women's health care providers' hold misconceptions about the IUD, which can be corrected with updated education on eligibility criteria for the IUD. 


\section{Queries and Answers}

Query: If there are any drug dosages in your article, please verify them and indicate that you have done so by initialing this query Answer: $\mathrm{CPE}$

Query: The journal uses an unstructured abstract. Please review the changes and adjust as appropriate.

Answer: ok, thank you

Query: The journal follows AMA style and the P value cannot $=000$. The P value is changed to $<.001$. Please confirm this is okay or provide the actual P value.

Answer: ok, thank you

Query: Because "CHOICE" is in all capital letters, this is assumed to be an acronym. If so, please provide an expansion.

Answer: It is not an acronym. This is how the researchers of that study refer to the study: Contraceptive CHOICE Project (CHOICE). It does not stand for anything, thank you.

Query: "New England State" is replaced with "Connecticut." If this is not the correct state, then adjust as appropriate.

Answer: yes, appropriate

Query: If Fairfield University is not the institution that approved the study then adjust as appropriate.

Answer: that is correct, thank you

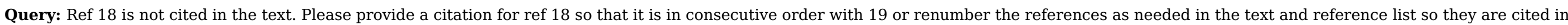
consecutive order

Answer: I have amended the citation, delete 16 and add 18

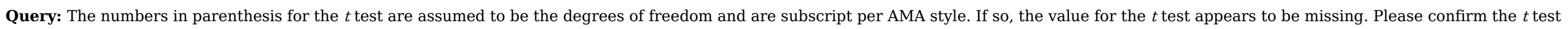
statistic is shown correctly as is or adjust as appropriate.

Answer: mean, 2.8; SD, $0.41 ; \mathrm{t}_{35}=-5.88, \mathrm{P}<.001$

Query: "Theme 4" here was assumed to be a typo and is changed to "Theme 3"

Answer: Yes, thank you

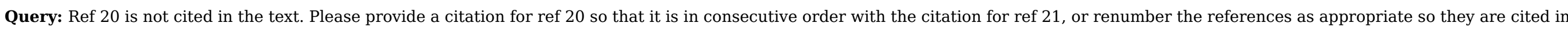
consecutive order.

Answer: I added the missing citation, thank you.

Query: Ref: Note that accessed dates and journal website addresses are not required if the doi and access is available through PubMed.

Answer: Thank you!

Query: The Table was not created using the Table tool and had to be redone. Please check that all data are shown on the correct data row.

Answer: thank you

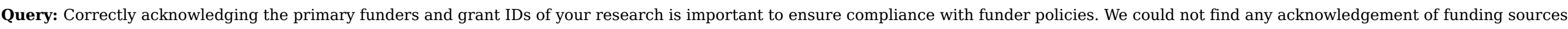




\section{Answer: Yes}

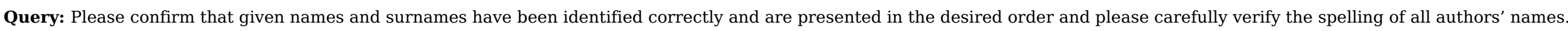
Answer: Yes

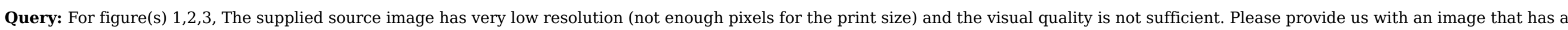
minimum resolution of $300 \mathrm{dpi}$ and with a proper print size (typically we need 900 pixels wide for an image that fits a single column). For more information, refer to

https://www.elsevier.com/authors/author-schemas/artwork-and-media-instructions/artwork-sizing.

Answer: Thank you

Attachments: JNP Revised Figure 1 Survey.jpg, JNP Revised Figure 2 Individual IUD Rates.jpg, JNP Revised Figure 3 Aggregate IUD Rates.jpg

Query: Note that journal follows AMA style and "utilization" is changed to "use" except in the case of "utilization rate" and "usage" is changed to "use" as well per AMA style.

Answer: ok, thank you 